\title{
Qualidade microbiológica de filés de tilápia do Nilo (Oreochromis niloticus) durante o armazenamento em gelo
}

\author{
Microbiological quality of the Nile tilápia (Oreochromis niloticus) fillets in ice storage
}

Karoline Mikaelle de Paiva Soares $^{*}$ Alex Augusto Gonçalves ${ }^{I}$ Lara Barbosa de Souza ${ }^{\text {II }}$

\section{RESUMO}

\begin{abstract}
O objetivo do presente trabalho foi avaliar o frescor microbiológico de filés sem pele de tilápia do Nilo (Oreochromis niloticus), cultivada durante o seu armazenamento em gelo. Os filés com peso médio de $120 \mathrm{~g}$ foram acondicionados em caixas isotérmicas, com gelo em escama, na proporção de 1:1 (filé: gelo). Estas caixas foram armazenadas em uma câmara fria, com temperatura externa e interna de aproximadamente $4^{\circ} \mathrm{C} e$ $0^{\circ} \mathrm{C}$, respectivamente. Realizaram-se análises microbiológicas a cada 72 horas, a partir do tempo zero, em triplicata. A qualidade microbiológica das amostras de tilápia foi aceitável durante o armazenamento.
\end{abstract}

Palavras-chave: tilápia, frescor, análise microbiológica.

\section{ABSTRACT}

The objective of this study was to evaluate the microbiological freshness of Nile tilapia (Oreochromis niloticus) skinless fillets, during storage in ice. The average weight of $120 \mathrm{~g}$ fillets were packed in cool boxes with scale ice, 1:1 ratio (fillet: ice). These boxes were stored in a cold room with internal and external temperature of about $4^{\circ} \mathrm{C}$ and $0^{\circ} \mathrm{C}$, respectively. Microbiological analyzes were performed every 72 hours from time zero in triplicate. The microbiological quality of the tilapia samples was acceptable during storage.

Key words: tilapia, freshness, microbiological analisys.

\section{INTRODUÇÃO}

Há uma tendência mundial de aumento no consumo de alimentos mais saudáveis, como a carne de pescado, que possui uma elevada importância nutricional. O termo pescado designa todo organismo aquático de origem fluvial, marinha ou estuarina, que pode ser utilizado na alimentação humana, como peixes, moluscos, crustáceos, anfíbios, quelônios, dentre outros (GONÇALVES, 2011). O pescado representa uma das principais fontes de proteínas na alimentação humana, sendo utilizado também na indústria de óleos, rações, farinha de peixe e outros produtos de alto valor comercial (ORDÓÑEZ, 2005). Apesar de possuir elevada importância do ponto de vista nutricional, o pescado é o alimento de origem animal com condições mais prováveis de deterioração, principalmente por apresentar $\mathrm{pH}$ próximo à neutralidade, elevada quantidade de água disponível para os micro-organismos, alto teor de nutrientes, elevado teor de ácidos graxos polinsaturados, estrutura muscular com menor barreira física de proteção, quando comparada à estrutura do músculo bovino, por exemplo, devido à baixa quantidade de tecido conjuntivo, rápida ação destrutiva das enzimas endógenas e exógenas presentes nos tecidos e nas vísceras, estresse acentuado no momento da captura, resultando em uma rápida instalação do rigor mortis e entre outros fatores intrínsecos e extrínsecos, que aumentam a susceptibilidade deste grupo alimentar ao processo de deterioração (GASPAR JR et al., 1997; LEITÃO et al., 1997; MASSAGUER, 2005; JAY, 2005).

O grau de frescor geralmente determina a qualidade do pescado. O emprego de ferramentas

IDepartamento de Ciências Animais, Universidade Federal Rural do Semi-Árido (UFERSA), Av. Francisco Mota, 572, Bairro Costa e Silva, 59625-900, Mossoró, RN, Brasil. E-mail: karolinemikaelle@ hotmail.com.*Autor para correspondência

IIPrograma de Pós-graduação em Ciência Animal, UFERSA, Mossoró, RN, Brasil. 
de avaliação do frescor durante todo período de comercialização desses produtos é fundamental para que seja possível o aproveitamento dos benefícios nutricionais. A segurança e a qualidade dos produtos alimentares são aspectos de grande relevância na atualidade, o que é confirmado pelo crescente número de leis que exigem a qualidade dos alimentos nas várias etapas da cadeia de produção. O frescor microbiológico é um importante critério de qualidade em pescado, já que o desenvolvimento microbiano é um dos principais fatores que levam à deterioração deste grupo alimentar (NUNES et al., 2007; ESTEVES \& ANÍBAL, 2007; GERMANO \& GERMANO, 2008; GONÇALVES, 2011).

Em pescado refrigerado, as bactérias psicrotróficas participam diretamente do processo de deterioração, pelo fato de se multiplicarem bem nessas condições. Esse grupo microbiano utiliza o pescado como substrato para realização de suas atividades metabólicas, produzindo substâncias que conferem aroma e sabor desagradável ao alimento (FRANCO \& LANDGRAF, 2008). Comissões internacionais, como a International Commissionon Microbiological Specifications Foods (ICMSF, 1986), preconizam como padrão microbiológico a contagem de micro-organismos mesófilos máxima de $10^{7} \mathrm{UFCg}^{-1}$ para pescado refrigerado. No Brasil, a Resolução RDC no12 de 2001 da Agência Nacional de Vigilância Sanitária (ANVISA) define os padrões microbiológicos para pescado.

A tilápia do Nilo (Orechromis niloticus) é uma importante espécie de pescado de origem africana, que foi introduzida nos diversos continentes. São peixes com grande rusticidade e facilidade de comercialização (ZANOLO \& YAMAMURA, 2006). EKNATH et al. (1993) apontam a tilápia do Nilo como uma espécie de destaque no cenário mundial da aquicultura. Esta espécie pode ser cultivada através de vários sistemas, como cultivos familiares em pequena escala e sistemas superintensivos (BENTSEN et al., 1998). Além disso, características como a carne branca de textura firme, sabor delicado, facilidade na filetagem, ausência de espinha em "Y" e de odor desagradável fazem com que esta espécie seja uma das mais preferidas pelos consumidores (SOUZA, 2002). Nesse sentido, o presente trabalho teve por objetivo avaliar a qualidade microbiológica de filés de tilápia do Nilo durante o armazenamento em gelo.

\section{MATERIAL E MÉTODOS}

Os exemplares de tilápia do Nilo (Orechromis niloticus), com peso médio de $650 \mathrm{~g}$, foram obtidos da Unidade Demonstrativa de Cultivo de Tilápias em Gaiolas (Apodi, RN, Brasil)e abatidos por hipotermia, em água com gelo, na proporção 1:1 (água:gelo; temperatura de aproximadamente $1{ }^{\circ} \mathrm{C}$ ). Após o abate, os peixes foram acondicionados em gelo e transportados ao Laboratório de Tecnologia de Alimentos da Universidade Federal Rural do Semi-Árido (UFERSA), onde foram filetados, com adoção de boas práticas de higiene durante a filetagem, seguido da remoção da pele e embalado em sacos plásticos. Os filés com peso médio $120 \mathrm{~g}$ foram acondicionados em caixas isotérmicas, com gelo em escama. Estas caixas foram armazenadas em uma câmara fria, com temperatura externa e interna de aproximadamente $4^{\circ} \mathrm{C}$ e $0^{\circ} \mathrm{C}$, respectivamente. A temperatura interna e externa das amostras durante o período de armazenamento foi aferida diariamente através de um termômetro digital.

As análises microbiológicas foram realizadas no Laboratório de Inspeção de Produtos de Origem Animal da UFERSA. Realizaram-se as análises para a contagem total de bactérias aeróbias mesófilas (CTB), contagem de Sthaphylococcus aureus coagulase positivo e determinação do Número Mais Provável (NMP) de coliformes totais e termotolerantes, utilizando metodologia proposta pela Instrução Normativa nº 62/2003 do Ministério da Agricultura, Pecuária e Abastecimento (MAPA) (BRASIL, 2003). A quantidade de microorgansimos pscicrotróficos foi determinada através de método citado por SANTOS et al. (2010).A avaliação microbiológica foi realizada durante todo o armazenamento, partindo-se de um tempo zero e repetindo-se em intervalos regulares de 72 horas.

Os dados obtidos foram plotados e analisados através de estatística descritiva. O gráfico com resultados das análises microbiológicas foi elaborado pelo software SIGMAPLOT for Windows v.10 (SystatSftware, Inc).

\section{RESULTADOS E DISCUSSÃO}

Através das médias da CTB, em função dos dias de estocagem de filés de tilápia do Nilo, observou-se rápido aumento inicial na CTB do tempo zero para o tempo três dias. Nos períodos intermediários de armazenamento dos filés, a partir do 6o ao $12^{\circ}$ dia, observou-se um pequeno incremento na CTB. Nos estágios finais de estocagem, ou seja, do $12^{\circ}$ dia ao $15^{\circ}$ e deste ao $18^{\circ}$, os incrementos nos valores das contagens foram bem superiores, quando comparados aos aumentos obtidos na fase intermediária (Figura 1). 


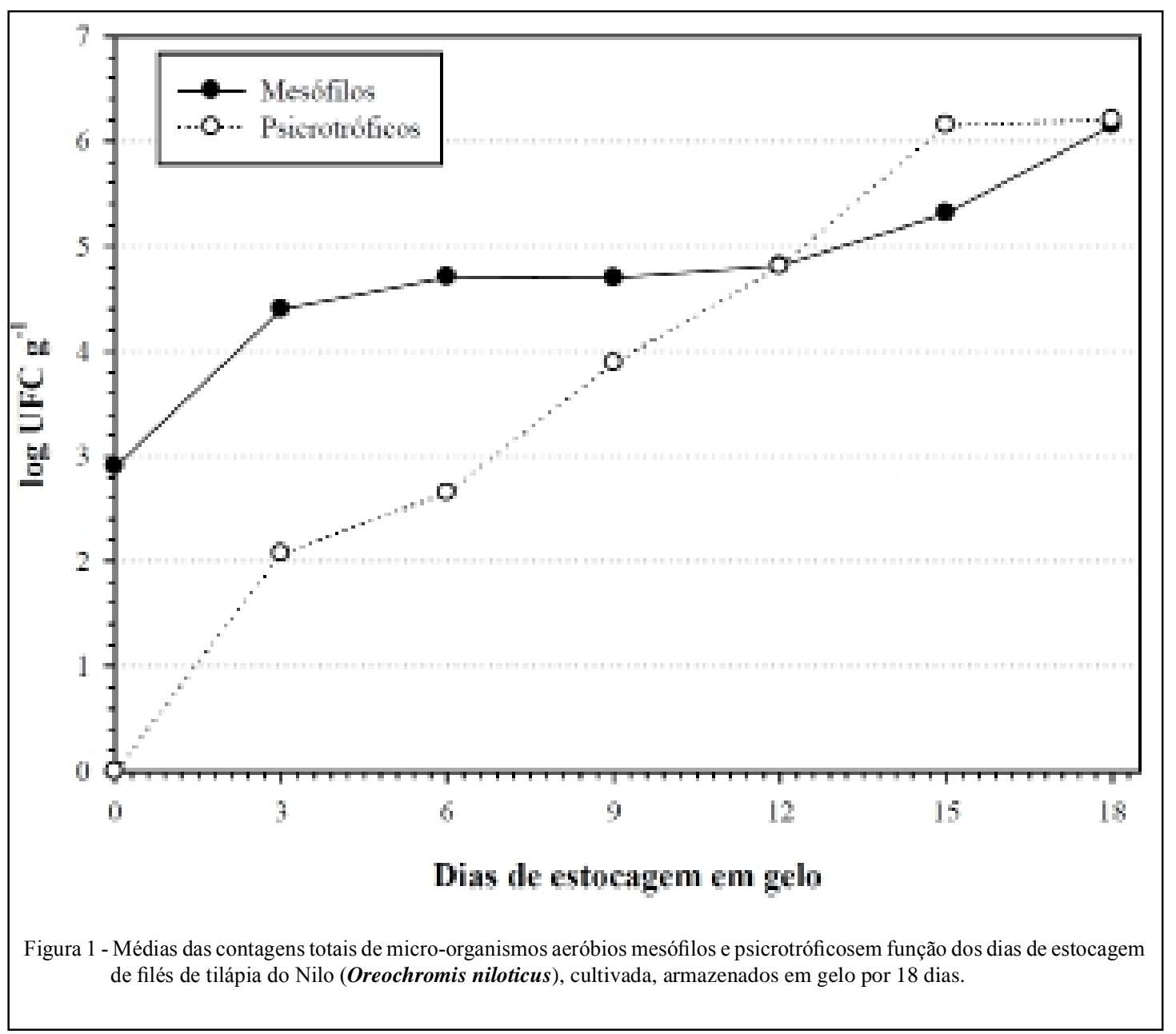

A CTB, durante o armazenamento, variou de $7,94 \times 10^{2} \mathrm{UFCg}^{-1}$, no tempo zero, e $1,41 \times 10^{6} \mathrm{UFCg}^{-1}$, aos 18 dias em gelo (Figura 1). As contagens de CTB não ultrapassaram os limites preconizados pela ICMSF (1986), que permite contagens máximas de $10^{7} \mathrm{UFCg}^{-1}$. Os resultados de CTB encontrados para filés de tilápia no presente estudo estão próximos daqueles registrados por BRITTO et al. (2007), que, ao trabalharem com outro peixe de água doce, o jaraqui, encontraram contagens de CTB variando de $1,3 \times 10^{2} \mathrm{UFCg}^{-1}$ (dia zero) a $1,9 \times 10^{6} \mathrm{UFCg}^{-1}$ no $18^{\circ}$ dia. CYPRIAN (2009) registrou contagens superiores a $10^{7} \mathrm{UFCg}^{-1}$ em filés de tilápia do Nilo armazenados a $-1{ }^{\circ} \mathrm{C}$. Enquanto BARRETO et al. (2012) detectaram contagem de bactérias mesófilas variando de $4,66 \times 10^{6}$ a $6,84 \times 10^{6} \mathrm{UFCg}^{-1} \mathrm{em}$ pescado fresco comercializado em Cruz das Almas-BA. ALVES et al. (2010) reforçam a importância da contagem de mesófilos na estimativa da vida útil do pescado.

No presente estudo, não foram registradas contagens de micro-organismos psicrotróficos em filés de tilápia no tempo zero. Houve crescimento de micro-organismos psicrotróficos a partir do $3^{\circ}$ dia de armazenamento, período no qual a contagem média foi de $1,1 \times 10^{2} \mathrm{UFCg}^{-1}$. O crescimento deste grupo de micro-organismospermaneceuemestágioexponencial até o 15o dia de estocagem, quando entrou em fase estacionária. Observa-se que não houve aumento significativo nas contagens do $15^{\circ}$ dia em relação ao $18^{\circ}$ dia (Figura 1). No $15^{\circ}$ dia de estocagem dos filés de tilápia do Nilo, a contagem de micro-organismos psicrotróficos foi de $1,4 \times 10^{6} \mathrm{UFCg}^{-1}$, permanecendo praticamente a mesma aos 18 dias, período no qual a contagem foi de $1,6 \times 10^{6} \mathrm{UFCg}^{-1}$. LANZARIN et al. (2011) analisaram a qualidade microbiológica do pintado (Pseudoplatystoma coruscans) estocado sob refrigeração e também detectaram ausência de psicrotróficos nos primeiros dias de armazenamento, observando valores de contagens microbiológicas variando de 0 a $6,54 \log \mathrm{UFCg}^{-1}$ para o referido grupo microbiano. LEITÃO et al. (1997) observaram baixa quantidade de psicrotróficos e mesófilos em 
pacu (Piaractus mesopotanicus) armazenado em refrigeração. SOCCOL et al. (2005), ao trabalharem com filés de tilápia, verificaram contagens de $2,0 \log \mathrm{UFCg}^{-1}$ no primeiro dia de estocagem em refrigeração e $7,25 \log \mathrm{UFCg}^{-1}$ no $20^{\circ}$ dia de armazenamento sob refrigeração. ABREU et al. (2008) realizaram análises microbiológicas em filés de peixe sapo (Lophiusgas trophysus) e observaram contagens de psicrotróficas a partir do dia zero de armazenamento $6,88 \log \left(7,5 \times 10^{6} \mathrm{UFCg}^{-1}\right)$.

LEITÃO et al. (1997), ao avaliarem a qualidade de pacu durante $\mathrm{o}$ armazenamento refrigerado a $5^{\circ} \mathrm{C}$, verificaram uma lenta multiplicação da microbiota deteriorante, observando que populações compatíveis com o processo de deterioração $\left(>7,0 \log \mathrm{UFCcm}^{-2}\right)$ foram atingidas após 14 dias de armazenamento. SOARES et al. (2011), ao analisar filés de peixes congelados distribuídos na cidade de Botucatu, obtiveram resultados variando de 0 a $9,0 \log \mathrm{UFCg}^{-1}$ para as mesófilas e de 0 a $9,1 \log \mathrm{UFCg}^{-1}$ para as psicrotróficas. Estes autores reforçam que as concentrações destes microorgansimos deteriorantes são fundamentais para indicar as condições higiênico sanitárias do pescado, bem como o seu estado de frescor.

Apesar da legislação brasileira não exigir limite para micro-organismos psicrotróficos, contagens elevadas desses micro-organismos deteriorantes reduzem a vida de prateleira do pescado, principalmente, por realizarem atividades proteolíticas e lipolíticas, e pela capacidade de crescimento e multiplicação em temperaturas de refrigeração (LANZARIN et al., 2011). A flora psicrotrófica de peixes e derivados é constituída principalmente por Pseudomonas spp., Alteromonas spp., Shewanella putrefasciens, Acinetobacter spp., Moraxella spp. (FORSYTHE, 2013).

As médias das contagens estimadas em NMP de coliformes totais foram baixas durante todo o armazenamento, variando de zero a $10,06 \mathrm{UFCg}^{-1}$. Outro fato que se observa é que não há um aumento gradativo nas contagens destes micro-organismos, ou seja, as contagens aumentaram até o 9o dia de análise. A partir do $12^{\circ}$ até $18^{\circ}$, as médias das contagens diminuíram, o que, possivelmente, associa-se a uma baixa resistência destes micro-organismos a temperaturas de refrigeração. Registrou-se ausência total de crescimento de coliformes termotolerantes durante todo o período de armazenamento dos filés de tilápia do Nilo (Tabela 1).

Os coliformes são micro-organismos indicadores de condições higiênico-sanitárias de produção e comercialização de alimentos. A presença destes micro-organismos indica provável contaminação fecal da água nos ambientes de captura (FRAZIER \& WESTHOFF, 1993; FARIAS, 2007). As baixas contagens de coliformes totais e termotolerantes reportadas no presente trabalho, provavelmente, estão relacionadas às boas condições higiênico sanitárias do ambiente no qual os peixes foram capturados. Além disso, a baixa ocorrência de coliformes, provavelmente, está associada à adoção de boas práticas de manipulação durante o processo de filetagem da tilápia do Nilo, realizado no presente estudo. SOCCOL (2002), em estudo com armazenamento refrigerado de filés de tilápia do Nilo submetidos a diferentes tratamentos, também detectou baixas contagens de coliformes, inclusive nas amostras do tratamento controle. Neste estudo, o autor encontrou contagens de coliformes totais variando de $>2 \mathrm{NMPg}^{-1}$ a $320 \mathrm{NMPg}^{-1}$, além de ausência de coliformes termotolerantes, ou seja, os resultados foram próximos aos encontrados no presente trabalho.

Verificou-se ausência de Staphylococcus aureus coagulase positivo durante todo o período de armazenamento dos filés de tilápia do Nilo. Apesar de ter ocorrido crescimento de Staphylococcus spp., as colônias reagiram negativamente ao teste da coagulase. As bactérias do gênero Staphylococcus são habitantes usuais da pele e mucosas de manipuladores, e, portanto, sua presença em baixos níveis ou sua ausência sugere adoção de boas práticas de higiene pelos manipuladores (GERMANO \& GERMANO, 2008). Resultados semelhantes a estes foram encontrados em pesquisa realizada por NORA et al. (2012), que analisaram filés de pescado oriundo de diferentes indústrias pesqueiras e verificaram ausência de Staphylococcus aureus coagulase positivo em todas as amostras. SIMÕES et al. (2007) avaliaram a qualidade microbiológica de filés de tilápia tailandesa e também detectaram ausência de Staphylococcus aureus coagulase positivo, enquanto RALL et al. (2011) detectaram S. aureus em 3\% das amostras de pescado coletadas na cidade de Botucatu. A RDC 12/2001 da Agência de Vigilância Sanitária estabelece como limite de tolerância de Staphylococcus aureus coagulase positivo, em pescado in natura resfriado, o valor de $10^{3} \mathrm{UFCg}^{-1}$, o que indica que os filés de tilápia avaliados no presente estudo apresentaram-se dentro dos padrões legais para o referido parâmetro durante todo o período de armazenamento.

Segundo BOARI et al. (2008), na cadeia de processamento de filés de tilápia, encontrase presente uma grande variedade de micro- 
Tabela 1- Médias doNúmero Mais Provável (NMP) de coliformes totais e termotolerantes em filés de tilápia do Nilo (Oreochromis niloticus) armazenados em gelo durante 18 dias.

\begin{tabular}{ccc}
\hline Dia & $\begin{array}{c}\text { NMP de coliformes } \\
\text { totais }\left(\mathrm{NMPg}^{-1}\right)\end{array}$ & $\begin{array}{c}\text { NMP de coliformes } \\
\text { termotolerantes }\left(\mathrm{NMPg}^{-1}\right)\end{array}$ \\
\hline 0 & $<3,00$ & $<3,00$ \\
3 & 2,20 & $<3,00$ \\
6 & 3,67 & $<3,00$ \\
9 & 10,06 & $<3,00$ \\
12 & 3,06 & $<3,00$ \\
15 & $<3,00$ & $<3,00$ \\
18 & 1,20 & $<3,00$ \\
\hline
\end{tabular}

organismos associados a doenças veiculadas por alimentos e à sua deterioração. MACHADO et al. (2010) verificaram que falhas na adoção de medidas higiênicas, desde a captura até a comercialização do pescado, comprometem sua qualidade final. Em tilápia cultivada, a qualidade da água de cultivo e a manipulação cuidadosa durante a filetagem são fundamentais na garantia da segurança microbiológica e no prolongamento da vida de prateleira dos filés.

\section{CONCLUSÃO}

A qualidade microbiológica dos filés de tilápia do Nilo diminuiu durante armazenamento em gelo. A CBT apresentou um rápido aumento inicial durante os primeiros dias de estocagem, porém não ultrapassou os limites de $10^{7} \mathrm{UFCg}^{-1}$, preconizados pela ICMSF, durante todo o período de armazenamento (18 dias). Verificou-se ausência de Staphylococcus aureus coagulase positivo e quantidades não significativas de coliformes totais e termotolerantes, o que indica boas condições higiênico sanitárias da água de cultivo e adoção de boas práticas durante o processamento. Assim, os filés de tilápia do Nilo apresentaram qualidade microbiológica satisfatória durante armazenamento em gelo por 18 dias, em todos os parâmetros avaliados.

\section{REFERÊNCIAS}

ABREU, M.G. et al. Caracterização sensorial e análise bacteriológica do peixe-sapo (Lophiusgastrophysus) refrigerado e irradiado. Ciencia Rural,v.38, n.2, p.498-503, 2008. Disponível em: <http://www. scielo.br/scielo.php?pid=S0103-84782008000200032\&script $=$ sci arttext\&tlng=es>. Acesso em: 01 jan. 2012. doi: 10.1590/S010384782008000200032 .

AGÊNCIA NACIONAL DE VIGILÂNCIA SANITÁRIA ANVISA. Resolução RDC -12 de 2 de janeiro de 2001 - D.O.U.de 10/01/2001.
ALVES, G. et al. Avaliação físico - química, microbiológica e sensorial de tilápias do Nilo (Oreochromis niloticus) inteiras evisceradas submetidas a salga e secagem natural. Arquivos de Ciências Veterinárias e Zoologia da UNIPAR, v.13, n.2, p.71-75, 2010. Disponível em: <http://revistas.unipar.br/veterinaria/article/ view/3722/2422>. Acesso em: 01 jan. 2012

BARRETO, N.S.E. et al. Avaliação das condições higiênicosanitárias do pescado comercializado no município de Cruz das Almas, Bahia. Revista Caatinga, v.25, n.3, p.86-95, 2012.

BENTSEN, H.B. et al. Genetic improvement of farmed tilapias: growth performance in a complete diallel cross experiment with eight strains of Oreochromis niloticus. Aquaculture,v.160, n.1/2, p. 145-173, 1998. Disponível em: <http://www.sciencedirect.com/ science/article/pii/S0044848697002305>. Acesso em: 01 jan. 2012. doi: 10.1016/S0044-8486(97)00230-5.

BOARI, C.A. et al. Bacterial ecology of tilapia fresh fillets and some factors that can influence their microbial quality. Ciência e Tecnologia de Alimentos, v.28, n.4, p.863-867, 2008. Disponível em: <http://www.scielo.br/scielo.php?script=sci_ar ttext\&pid=S0101-20612008000400015>. Acesso em: 01 jan. 2012. doi: 10.1590/S0101-20612008000400015.

BRASIL. Ministério da Agricultura, Pecuária e Abastecimento. Instrução Normativa $n^{\circ} 62$, de 26 de agosto de 2003. Oficializa os Métodos Analíticos Oficiais para Análises Microbiológicas para Controle de Produtos de Origem Animal e Água. Diário Oficial da União, Brasília, 26 de agosto de 2003. Seção 1.

BRITTO, E.N. et al. Deterioração bacteriológica do jaraqui Semaprochilodus spp. capturado no estado do Amazonas e conservado em gelo. Acta Amazonica, v. 37, n.3, p. 457-464, 2007. Disponível em: <http://www.scielo.br/scielo.php?pid=S004459672007000300018\&script=sci_arttext $>$. Acesso em: 01 jan. 2012. doi: 10.1590/S0044-59672007000300018.

CYPRIAN, O. Optimal storage conditions for fresh farmed tilapia (Oreochromis niloticus) fillets. 2009. 84f. Thesis (Masters in science) - University of Iceland.

EKNATH, A.E. et al. Genetic improvement of farmed tilapias: the growth performance of eight strains of Oreochromis niloticus tested in different farm environments. Aquaculture, v.111, n.1/4, p.171-188, 1993. Disponível em: <http://www.sciencedirect.com/ science/article/pii/004484869390035W $>$. Acesso em: 01 jan. 2012. doi: 10.1016/0044-8486(93)90035-W.

ESTEVES, E.; ANIBAL, J. Quality Index Method(QIM): utilização da análise sensorial para determinação da qualidade do pescado. In: CONGRESSO DO ALGARVE, 13., 2007, Lagos. Anais... Lagos: [s.n.], 2007. p.365-373.

FARIAS, M.C.A. Avaliação das condições higiênico-sanitárias do pescado beneficiado em indústrias paraenses e aspectos relativos à exposição para consumo em Belém, Pará. Revista do Instituto Adolfo Lutz, v.66, n.2, p.206, 2007. Disponível em: <http://revistas. bvs-vet.org.br/rialutz/article/view/7767/7989>. Acesso em: 01 jan. 2012 .

FORSYTHE, S.J. Microbiologia da segurança dos alimentos. 2.ed. Porto Alegre: Artmed, 2013. 607p.

FRANCO, B.D.G.M.; LANDGRAF, M. Microbiologia de alimentos. São Paulo: Atheneu, 2008. 182p. 
FRAZIER, W.C.;WESTHOFF, D.C. Microbiología de losalimentos. 4.ed. Zaragoza: Acribia, 1993.681p.

GASPAR JR, J.C et al. Aspectos sanitários do pescado de origem de água doce e marinha, comercializado nafeira de Gentilândia, Fortaleza, Ceará. Higiene Alimentar, v.11, p.20-23,1997.

GERMANO, P.M.L.; GERMANO, P.M.L. Higiene e vigilância sanitária de alimentos. 3.ed. São Paulo: Manole, 2008. 986p.

GONÇALVES, A.A. Tecnologia do pescado: ciência, tecnologia, inovação e legislação. São Paulo: Ateneu, 2011. 608p.

ICMSF (INTERNATIONAL COMMISSION ON MICROBIOLOGICAL SPECIFICATIONS FOR FOODS). 2. Sampling for microbiological analysis: principles and specific applications. 2.ed. London: Blackwell Scientific Publications, $1986.131 \mathrm{p}$

JAY, J.M. Microbiologia de alimentos. 6.ed. Porto Alegre: Artmed, 2005. 711p.

LANZARIN, M. et al. Ocorrência de Aeromonas sp. e microrganismos psicrotróficos e estimativa do prazo de validade comercial de filé de pintado (Pseudoplatystoma coruscans) mantidos sob refrigeração. Arquivo Brasileiro de Medicina Veterinária e Zootecnia, v.63, n.6, p.1541-1546, 2011. Disponível em: <http://www.scielo.br/scielo.php?pid=S010209352011000600035\&script=sci_arttext $>$. Acesso em: 01 jan. 2012. doi: 10.1590/S0102-09352011000600035.

LEITÃO, M.F.F. et al. Alterações químicas e microbiológicas em pacu (Piaractus mesopotamicus) armazenado sob refrigeração a $5^{\circ} \mathrm{C}$. Ciência e Tecnologia de Alimentos, v.17, p.160-166, 1997. Disponível em: <http://www.scielo.br/scielo.php?pid=S01012061 $1997000200018 \&$ script=sci_arttext\&tlng=es $>$. Acesso em: 01 jan. 2012. doi: 10.1590/S0101-20611997000200018.

MACHADO, T.M. et al. Fatores que afetam a qualidade do pescado na pesca artesanal de municípios da costa sul de São Paulo, Brasil. Boletim do Instituto de Pesca, v.36, n.2, p.213-223, 2010. Disponível em: <ftp://ftp.sp.gov.br/ftppesca/36_3_213-223. pdf $>$. Acesso em: 01 jan. 2012.

MASSAGUER, P.R. Microbiologia dos processos alimentares. São Paulo: Varela, 2005. 258p.

NORA, N.S. et al. Avaliação microbiológica de filés de pescados oriundos de diferentes indústrias pesqueiras. Online. Disponível em: <http://www.ufpel.edu.br/cic/2009/cd/pdf/CA/CA_01314. pdf>. Acesso em: 01 jan. 2012.

NUNES, M.L. et al. Application of Quality Index (QIM) in the evaluation of the freshness of fish. Lisboa: IPIMAR, 2007. 51p.
ORDÓÑEZ, J.A. Tecnologia de alimentos de origem animal. São Paulo: Artmed, 2005.V.2. 279p.

RALL, V.L.M. et al. Qualidade microbiológica de pescado comercializado na cidade de Botucatu, SP. Higiene Alimentar, v.25, n.192/193, p.123-125, 2011.

SANTOS, E.B. et al. Radiação gama na redução da microbiota de carne de siri (Callinectes sapidus) pré-cozida, congelada e inspecionada. Boletim do Instituto de Pesca, v.36, n.3, p.175183, 2010. Disponível em: <ftp://ftp.sp.gov.br/ftppesca/36_3_175183rev.pdf>. Acesso em: 01 jan. 2012.

SIMÕES, M.R. et al. Composição físico-química, microbiológica e rendimento do filé de tilápia tailandesa (Oreochromis niloticus). Ciência e Tecnologia de Alimentos, v.27, n.3, p.608-613, 2007. Disponível em: <http://www.scielo.br/scielo.php?pid=S0101$20612007000300028 \&$ script=sci_arttext $>$. Acesso em: 01 jan. 2012. doi: 10.1590/S0101-20612007000300028.

SOARES, V.M. et. al. Qualidade microbiológica de filés de peixe congelados distribuídos na cidade de Botucatu - SP. UNOPAR Científica Ciências Biológicas e da Saúde, v.13, n.2, p.8588, 2011. Disponível em: <http://revistas.unopar.br/index.php/ biologicas/article/view/329/319>. Acesso: 01 jan. 2012.

SOCCOL, M.C.H. Otimização da vida útil da tilápia cultivada (Orechoromisniloticus), minimamente processada e armazenada sob refrigeração. 2002. 124f. Dissertação (Mestrado em Ciências) - Curso de Pós-graduação em Ciências, Escola Superior de Agricultura Luiz de Queiroz, Universidade de São Paulo, SP.

SOCCOL, M.C.H. et al. Effects of modified atmosphere and vacuum on the shelf-life of tilapia (Oreochoromis niloticus) fillets. Brazilian Journal of Food Technology (impresso), v.8, n.1, p.7$15,2005$.

SOUZA, M.R.L. Comparação de seis métodos de filetagem, em relação ao rendimento de filé e de subprodutos do processamento da Tilápia-do-Nilo (Oreochromis niloticus). Revista Brasileira de Zootecnia, v.31, n.3, p.1076-1084, 2002. Disponível em: <http://www.scielo.br/scielo.php?script=sci_arttext\&pid=S15163 $5982002000500003 \& \operatorname{lng}=\mathrm{en} \& n r m=i s o \& \operatorname{lng}=\mathrm{pt}>$. Acesso: 01 jan. 2012. doi: 10.1590/S1516-35982002000500003.

ZANOLO, R.; YAMAMURA, M.H. Parasitas em tilápias-do-nilo criadas em sistema de tanques-rede. Semina: Ciências Agrárias, v.27, n.2, p.281-288, 2006. Disponível em: <http://dx.doi. org/10.5433/1679-0359.2006v27n2p281>. Acesso: 01 jan. 2012. doi: 10.5433/1679-0359.2006v27n2p281. 